\title{
INFLUENCE OF THE EXTRACTION PARAMETERS OF ANTOCIANES FROM THE FRUITS OF ARONIA MELANOCARPA (MICHX.) ELLIOTT IN THE EXTRACTION ASSISTED WITH ULTRASOUND. PRELIMINARY RESULTS
}

\author{
Alin Din ${ }^{1}$, Denisa Ştefania Vîlcoci ${ }^{1}$, Cătălin Ducu ${ }^{{ }^{*}}$, Anca Nicoleta Şuțan ${ }^{1}$, Sorin Moga ${ }^{1}$, \\ Dorin Ioan Sumedrea ${ }^{2}$, Andrei Biță ${ }^{3}$, Ludovic-Everard Bejenaru ${ }^{3 *}$, George-Dan Mogoşanu ${ }^{3}$ \\ ${ }^{1}$ University of Pitesti, Targul din Vale 1, 110040 Pitesti, Romania \\ ${ }^{2}$ Research Institute for Fruit Growing Pitesti, Strada Mărului nr. 402, 117450 Mărăcineni, Romania \\ ${ }^{3}$ Department of Pharmacy II, Faculty of Pharmacy, Discipline Pharmacognosy - Phytotherapy, \\ University of Medicine and Pharmacy of Craiova, Petru Rareş nr. 2, 200349 Craiova, Romania
}

\begin{abstract}
In recent years, more and more studies have highlighted the potential of fruits of Aronia melanocarpa (Michx.) Elliott for the pharmaceutical and cosmetic industry, due to the high content of polyphenols and anthocyanins. Currently, the use of agricultural production of Aronia melanocarpa is mainly done through the use of fruit juice or powders in the food industry. In the present study we set out to achieve a superior route of fruit valorization by obtaining extracts for the pharmaceutical and cosmetics industry. For ultrasound-assisted extraction, Aronia melanocarpa fruits were preprocessed (drying, grinding, sieving) and then subjected to ultrasonic-assisted solvent extraction.

The study carried out in this phase of the experiment followed the influence of the concentration of the solvent (water/ethanol ratio) on the anthocyanin content and the chromatographic profile of the extract. The chromatographic profile was obtained using the HPTLC method. The analysis material was represented by 3 extracts obtained under various experimental conditions, from the species Aronia melanocarpa (Michx.) Elliot fruits.

The best HPTLC chromatographic imprint was shown for Aronia fruit extracts prepared in 3:1 water-ethanol mixture, at amplitude of $40 \%$. In the other experimental variants the anthocyanin content was low.
\end{abstract}

Keywords: pharmaceutical and cosmetic industry, polyphenols and anthocyanins, ultrasonic assisted extraction.

\section{INTRODUCTION}

Aronia melanocarpa (Michx.) Elliott, black chokeberry black (Rosaceae), is a shrub native to North America, naturalized in Europe and Asia. It is widely grown as an ornamental plant (through flowers, leaves), but especially for its fruit with uses in the fruit growing/food industry (juices, jams, wines) (Valcheva-Kuzmanova et Belcheva, 2006; Kokotkiewicz et al., 2010; Banjari et al., 2017). From a phytochemical point of view, Aronia melanocarpa fruits (Aroniae melanocarpae fructus) mainly contain active antioxidant components: anthocyanosides (cyanidol-3-O-galactoside, cyanidol-3-O-glucoside, cyanidol-3-O-arabinoside, cyanidol-3-O-xyloside), proanthocyanidols, flavonols (quercetol), flavonozides (quercetol-3-O-glucoside, quercetol-3-O-rutinozide), resveratrol, catechin tannin [(-) - epicatechol], triterpenoids, polyphenolcarboxylic acids 
(chlorogenic acid, neochlorogenic acid), vitamins (ascorbic acid) (Valcheva-Kuzmanova et Belcheva, 2006; Yu et al., 2007; Kokotkiewicz et al., 2010; Banjari et al., 2017; Denev et al., 2018; Gralec et al., 2019; Kobus et al., 2019). The medicinal product Aroniae melanocarpae fructus, has remarkable pharmacological actions: antioxidant, antimutagenic, radioprotective, antitumor, immunomodulatory, cardioprotective, antidiabetic, hepatoprotective, uricosuric, gastroprotective, anti-inflammatory, antimicrobial and antiviral (Valcheva-Kuzmanova et Belcheva, 2006; KrajkaKuźniak et al., 2009; Kokotkiewicz et al., 2010; Banjari et al., 2017; Cebova et al., 2017; Denev et al., 2018; Kobus et al., 2019; Wang et al., 2019). In recent years, there has been an increase in the demand for natural extracts obtained by "green", non-conventional raw material processing techniques. These techniques have also been developed to solve the problems that arise when using conventional extraction methods. The "green" technique can be defined as an "extraction method that is based on the discovery and design of extraction processes that will reduce energy consumption, allowing the use of alternative solvents and renewable natural products and ensuring a safe and high quality extract / product". Compared to the classic maceration, the reasons why ultrasound assisted extraction (UAE) is considered a "green" or "ecological" technique are represented by the reduced consumption of fossil energy and the reduction of solvent use resulting in higher extraction yields, in a relatively short time (Carrera et al., 2012; Chemat et al., 2015; Tiwari, 2015). Ultrasonic assisted extraction has high efficiency, although it requires low energy, small amounts of solvent and short periods of time for the extraction process. The main advantage of this method is the production of the cavitation phenomenon involving local pressures and temperatures of hundreds of atmospheres and thousands of degrees Celsius. The aim of this study was to identify the best extraction parameters in order to obtain an optimal amount of anthocyanins.

\section{MATERIALS AND METHODS}

The material to be analyzed was represented by the fruits of the species Aronia melanocarpa (Michx.) Elliott (NERO variety) cultivated at the Institute for Research and Development for Pomiculture (ICDP) Piteşti-Mărăcineni, Arges County. For ultrasound-assisted extraction, the fruits of Aronia melanocarpa (Michx.) Elliot were preliminary processed by drying, grinding and sieving. The extract was accomplished with an ultrasonic extraction equipment model HIELSCHER UIP 1000hDT in order to obtain the following experimental variants:

Aronia_1: water:alcohol ratio - 3:1; plant:solvent ratio - 1:10; Time: $5 \mathrm{~min}$; Amplitude: 40\%;

Aronia_2: water:alcohol ratio - 3:1; plant:solvent ratio - 1:10; Time: $5 \mathrm{~min}$; Amplitude: 60\%;

Aronia_3: water:alcohol ratio - 3:1; plant:solvent ratio - 1:10; Time: $5 \mathrm{~min}$; Amplitude: 80\%.

High-performance Thin Layer Chromatography (HPTLC) can separate and identify a number of anthocyanin derivatives for fingerprint analysis under the following experimental conditions (Filip et al., 2012; Bräunlich et al., 2013; Lee, 2019):

stationary phase HPTLC silica gel G 60 F254, preformed glass plates $20 \times 10 \mathrm{~cm}$ (Merck,

Darmstadt, Germania);

- $\quad$ stationary phase pre-wash: chloroform-methanol mixture $(1: 1, \mathrm{v} / \mathrm{v})$;

- $\quad$ activation of the stationary phase: drying in the oven $\left(110^{\circ} \mathrm{C}, 30\right.$ minutes $)$;

- mobile phase: mixture of ethyl acetate-methyl ethyl ketone-water-formic acid (7:3:2:2, $\mathrm{v} / \mathrm{v} / \mathrm{v} / \mathrm{v}), 20 \mathrm{ml}$ in the chromatographic tank, with supersaturation for 20 minutes at $25^{\circ} \mathrm{C}$;

- $\quad$ samples to be analyzed, for HPTLC fingerprint: extracts of Aroniae melanocarpae fructus, diluted 1:4 (dilution factor 5) with ethanol; 
- $\quad$ migration distance: $62 \mathrm{~mm}$ (the sample application line was set at $8 \mathrm{~mm}$ and the solvent front set at $70 \mathrm{~mm}$ );

- the volumes applied to the starting line: $1 \mu \mathrm{l}$ of each sample to be analyzed (diluted previously with 1: 4 with ethanol);

the samples to be analyzed were applied by spray, in the form of strips with a length of 5 $\mathrm{mm}$, using the semi-automatic system CAMAG Linomat 5 (CAMAG, Muttenz, Switzerland): gasair spray, syringe volume - $100 \mu \mathrm{l}$, solvent in syringe - ethanol, application speed - $30 \mathrm{nl} / \mathrm{s}$, predose volume - $0.2 \mu \mathrm{l}$; blower);

- $\quad$ examination (detection): in visible (VIZ) (for photographing the chromatographic plate and at $\lambda 520 \mathrm{~nm}$, for obtaining the densitograms), without derivatization (respectively chemical treatment), using the CAMAG TLC Scanner 3 photo-densitometer: the chromatographic plate scan speed - $20 \mathrm{~mm} / \mathrm{s}$, resolution - $100 \mu \mathrm{m}$, lamp - deuterium and tungsten, measurement mode absorption. The solvents used for HPTLC analysis (LiChrosolv®) were sourced from Merck Millipore (Darmstadt, Germany).

\section{RESULTS AND DISCUSSIONS}

The analysis material was represented by 3 extracts obtained under various experimental conditions, from the species Aronia melanocarpa (Michx.) Elliot fruits cultivated at the Research Development Institute for Pomiculture (ICDP) Piteşti-Mărăcineni, județul Argeş.

By high performance thin layer chromatography (HPTLC - High-Performance Thin Layer Chromatography) a series of anthocyanin-derivatives can be separated and identified, for fingerprint analysis, in the following experimental conditions (Bräunlich et al., 2013; Filip et al., 2012; Lee, 2019).

Data on HPTLC fingerprint analysis for anthocyanin-derived content of Aroniae melanocarpae fructus extracts, obtained under various experimental conditions (No.1, No.2, No. 3), are presented, as follows, in Figures 1-3 and in Table 1.

Table 1 - HPTLC fingerprint analysis results for anthocyanin-derived content of Aroniae melanocarpae fructus extracts (according to densitograms)

\begin{tabular}{|c|c|c|c|c|c|}
\hline $\begin{array}{c}\text { The extract } \\
\text { analyzed }\end{array}$ & $\begin{array}{c}\text { Peak } \\
\text { No. }\end{array}$ & $\mathbf{R}_{\mathbf{f}}$ & {$\left[\right.$ AU - Area Units] $\times \mathbf{1 0}^{-\mathbf{3}}$} & Area [\%] & Observations \\
\hline \multirow{3}{*}{ Aronia_1 } & 1. & 0.24 & 0.96 & 6.87 & \\
\cline { 2 - 6 } & 2. & 0.55 & 9.23 & 66.43 & Cyanidol derivative \\
\cline { 2 - 6 } & 3. & 0.67 & 3.71 & 26.7 & \\
\hline \multirow{2}{*}{ Aronia_2 } & 1. & 0.56 & 2.91 & 69.76 & Cyanidol derivative \\
\cline { 2 - 6 } & 2. & 0.68 & 1.26 & 69.24 & \\
\hline \multirow{2}{*}{ Aronia_3 } & 1. & 0.56 & 3.06 & 30.97 & Cyanidol derivative \\
\cline { 2 - 6 } & 2. & 0.68 & 1.37 & \\
\hline
\end{tabular}

By HPTLC coupled with photodensitometry, in 3 extracts obtained under various experimental conditions, from the fruits of the species Aronia melanocarpa, anthocyanin-like components (mainly a cyanidol derivative) were separated and identified from the phytochemical footprint). The best HPTLC chromatographic imprint was shown for Aronia fruit extracts prepared in 3:1 waterethanol mixture, at amplitude of $40 \%$. The experimental results are in agreement with the 
Current Trends in Natural Sciences

Vol. 9, Issue 17, pp. 296-300, 2020

https://doi.org/10.47068/ctns.2020.v9i17.037

Current Trends in Natural Sciences (on-line)

ISSN: 2284-953X

ISSN-L: 2284-9521
Current Trends in Natural Sciences (CD-Rom)

ISSN: 2284-9521

ISSN-L: 2284-9521

information from the specialized works regarding the anthocyanin-derivatives content of the fruits of the species Aronia melanocarpa (Michx.) Elliot (Bräunlich et al., 2013; Denev et al., 2018; Gralec et al., 2019; Kobus et al., 2019). Chromatographic analysis is preliminary in nature, following only the specific fingerprint for anthocyanin derivatives, without the use of specific reference substances (standards).

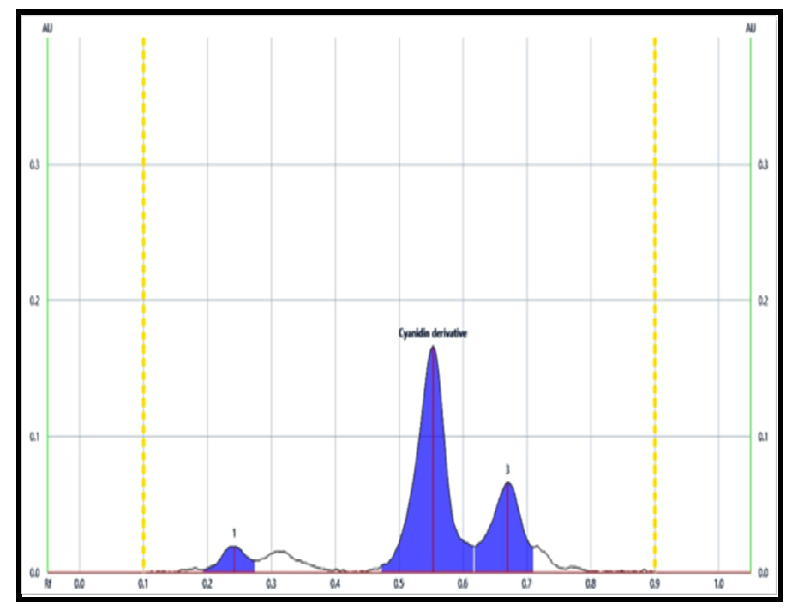

Figure 1 - Densitogram of the anthocyanin derivatives separated from the extract of Aroniae melanocarpae fructus No.1 (Aronia_1) (VIZ a $520 \mathrm{~nm}$, without derivatization)

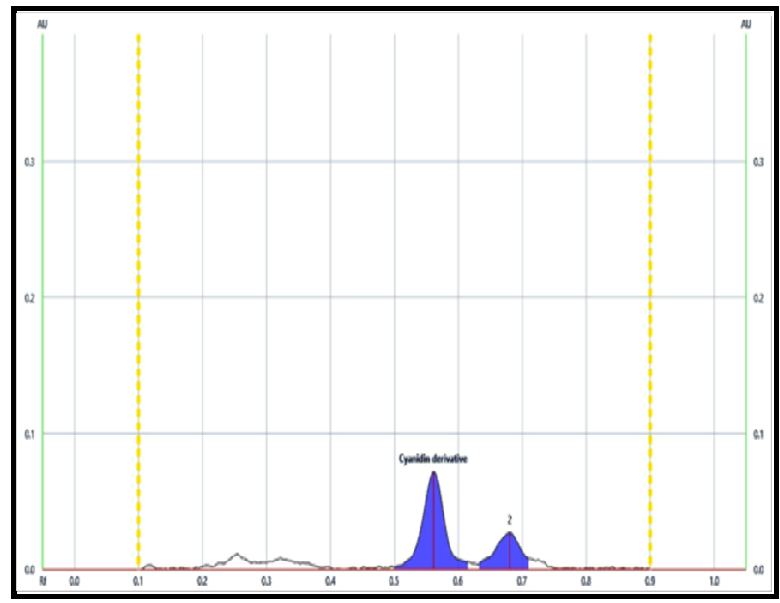

Figure 2 - Densitogram of the anthocyanin derivatives separated from the extract of Aroniae melanocarpae fructus No.2 (Aronia_2) (VIZ ג $520 \mathrm{~nm}$, without derivatization)

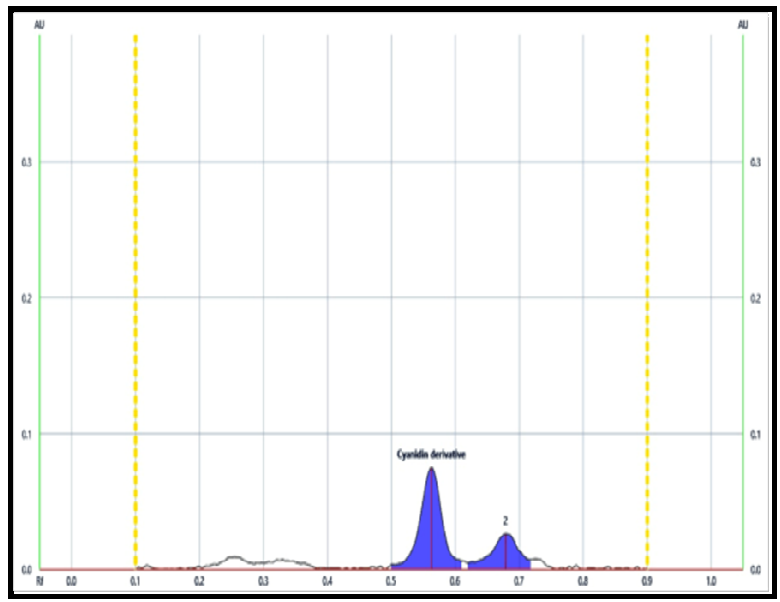

Figure 3 - Densitogram of the anthocyanin derivatives separated from the extract of Aroniae melanocarpae fructus

No.3 (Aronia_3) (VIZ ג 520 nm, without derivatization)

\section{CONCLUSIONS}

The best HPTLC chromatographic imprint is recorded for Aronia fruit extract prepared in 3:1 water-ethanol mixture at an amplitude of $40 \%$. 
The experimental results are in agreement with the information from the specialized papers regarding the anthocyanin-derivative content of the fruits of Aronia melanocarpa (Michx.) Elliot. A considerable advantage of the ultrasonic assisted extraction method is that it is a versatile technique, which can be used both in research experiments in experimental laboratories, on a small scale and on an industrial scale. Also, this method demonstrates that it is an efficient extraction technique of plant compounds that can be used at industrial level.

\section{ACKNOWLEDGEMENTS}

This work was supported by a grant of the Romanian Ministery of Research and Innovation, CCCDIUEFISCDI, project number PN-III-P1-1.2-PCCDI-2017-0332 "Increasing the institutional capacity of bioeconomic research for the innovative exploitation of a local plant resource resource, in obtaining high value-added horticultural products (BIOHORTINOV) "project component: "Innovative technologies for advanced processing of domestic plant resources" financing contract no.6 PCCDI / 2018.

\section{REFERENCES}

Banjari, I., Misir, A., Šavikin, K., Jokić, S., Molnar, M., De Zoysa, H.K.S., Waisundara, V.Y. (2017). Antidiabetic effects of Aronia melanocarpa and its other therapeutic properties. Front Nutr, 4, 53.

Bräunlich, M., Slimestad, R., Wangensteen, H., Brede C., Malterud, K.E., Barsett, H. (2013). Extracts, anthocyanins and procyanidins from Aronia melanocarpa as radical scavengers and enzyme inhibitors. Nutrients, 5(3), 663678.

Carrera, C., Ruiz-Rodríguez, A., Palma, M., Barroso, C.G. (2012). Ultrasound assisted extraction of phenolic compounds from grapes. Anal Chimical Acta, 732, 100-104.

Cebova, M., Klimentova, J., Janega, P., Pechanova, O. (2017). Effect of bioactive compound of Aronia melanocarpa on cardiovascular system in experimental hypertension. Oxid Med Cell Longev, 2017, 8156594.

Chemat, F., Fabiano-Tixie, A.S., Abert Vian, M., Allaf, T., Vorobiev, E. (2015). Solvent-free extraction of food and natural products. Trend Anal Chem, 71, 157-168.

Denev, P., Kratchanova, M., Petrova, I., Klisurova, D., Georgiev, Y., Ognyanov, M., Yanakieva, I. (2018). Black chokeberry (Aronia melanocarpa (Michx.) Elliot) fruits and functional drinks differ significantly in their chemical composition and antioxidant activity. J Chem, 9574587.

Filip, M., Vlassa, M., Copaciu, F., Coman, V. (2012). Identification of anthocyanins and anthocyanidins from berry fruits by chromatographic and spectroscopic techniques to establish the juice authenticity from market. $J$ Planar Chromatogr, 25(6), 534-541.

Gralec, M., Wawer, I., Zawada, K. (2019). Aronia melanocarpa berries: phenolics composition and antioxidant properties changes during fruit development and ripening. Emir J Food Agric, 31(3), 214-221.

Kobus, Z., Nadulski, R., Wilczyński, K., Kozak, M., Guz, T., Rydzak, L. (2019). Effect of the black chokeberry (Aronia melanocarpa (Michx.) Elliott) juice acquisition method on the content of polyphenols and antioxidant activity. PLoS One, 14(7), e0219585.

Kokotkiewicz, A., Jaremicz, Z., Luczkiewicz, M. (2010). Aronia plants: a review of traditional use, biological activities, and perspectives for modern medicine. J Med Food, 13(2), 255-269.

Krajka-Kuźniak, V., Szaefer, H., Ignatowicz, E., Adamska, T., Oszmiański, J., Baer-Dubowska, W. (2009). Effect of chokeberry (Aronia melanocarpa) juice on the metabolic activation and detoxication of carcinogenic $\mathrm{N}$ nitrosodiethylamine in rat liver. J Agric Food Chem, 57(11), 5071-5077.

Lee, H.Y. (2019). Optimization of cyanidin-3-O-galactoside production from Aronia melanocarpa Elliot from nonthermal ultrasonic extraction process by response surface methodology. Appl Sci, 9(6), 1203.

Tiwari, B.K. (2015). Ultrasound: A clean, green extraction technology. Trend Anal Chem, 71, 100-109.

Valcheva-Kuzmanova, S.V., Belcheva, A. (2006). Current knowledge of Aronia melanocarpa as a medicinal plant. Folia Med (Plovdiv), 48(2), 11-17.

Wang, Z., Wang, X., Yan, H., Liu, Y., Li, L., Li, S., Wang, X., Wang, D. (2019). Aronia melanocarpa ameliorates gout and hyperuricemia in animal models. Food Agric Immunol, 30(1), 47-59.

Yu, M., Li, X., Zhao, C.C., Xu, J., Zhang, P. (2007). Triterpene constituents from the seedling of Aronia melanocarpa. J Asian Nat Prod Res, 9(3-5), 365-372. 